\section{СНИЖЕНИЕ}

НЕФРОТОКСИЧНОСТИ

ПРОВЕДЕНИЕМ

ПЕРИТОНЕАЛЬНОГО

ДИАЛИЗА С ВКЛЮЧЕНИЕМ

ГИДРОКАРБОНАТА НАТРИЯ

ПРИ ОТРАВЛЕНИИ КРЫС

УРАНИЛ АЦЕТАТОМ

ДИГИДРАТОМ
К.В. Сивак ${ }^{1}$,

Т.Н. Саватеева-Любимова ${ }^{1}$,

Т.А. Гуськова ${ }^{2}$, Р.Г. Гусейнов

${ }^{1}$ Федеральное государственное бюджетное учреждение «Научно-исследовательский институт гриппа имени А.А. Смородинцева" Министерства здравоохранения Российской Федерации (ФГБУ "НИИ гриппа им. А.А. Смородинцева" Минздрава России), 197376, г. Санкт-Петербург, Российская Федерация

${ }^{2}$ Центр трансфера фармацевтических технологий им. М.В. Дорогова Ярославского государственного педагогического университета им. К.Д. Ушинского, 150010 , г. Ярославль, Российская Федерация ${ }^{3}$ Санкт-Петербургское государственное бюджетное учреждение здравоохранения Клиническая больница Святителя Луки (СПб ГБУЗ Клиническая больница Святителя Луки), 194044, СанктПетербург, Российская Федерация

статье представлены результаты экспериментального исследования при отравлении крыс уранил ацетатом дигидратом $\left(1 \times \mathrm{LD}_{50}\right)$. Целью данной работы являлось изучение эффективности включения гидрокарбоната натрия в состав раствора для перитонеального диализа в отношении клиренса урана и выживаемости крыс. Процедуру перитонеального диализа проводили в «остром» режиме 1 день в течение 5 часов. Каждая крыса получала суммарно 6 заполнений брюшного пространства и 6 сливов ультрафильтрата. Разница при включении в состав стандартного раствора гидрокарбоната натрия (Б, 1,5\%) составила для рН $\Delta=1,71, \mathrm{EC} \Delta=5055$ мкСм/см и TDS $\Delta=2527$ мг/л. Введение раствора Б привело к увеличению скорости перитонеального клиренса урана $\mathrm{PCl}\left[{ }^{238} \mathrm{U}\right]$ на 276,2\% (p=0,0286, критерий Манна-Уитни) по сравнению со стандартным раствором А без натрия гидрокарбоната. Динамика ультрафильтрации характеризовалась линейным ростом от 1 до 3 сеанса (угол наклона линейной регрессии 70) с выходом на плато к 3 сеансу. Величина URR составила 65,4\% в 1-е сутки, 65\% в 3-е сутки и 69,1\% на 7-е сутки наблюдения. Результаты теста Мантела-Кокса показали, что перитонеальный диализ с добавлением гидрокарбоната натрия в качестве антидота (раствор Б) способствовал достоверному увеличению постдиализной выживаемости крыс ( $=0,0018$ по сравнению с группой негативного контроля, $\mathrm{p}=0,0425$ по сравнению с диализом раствором А).

Ключевые слова: уран, $\left[{ }^{238} \mathrm{U}\right]$, крысы, острое повреждение почек, «острый» перитонеальный диализ, перитонеальньй клиренс, ультрафильтрация, $\left.P C l{ }^{238} U\right], U R R$

Введение. Ренальная форма острого повреждения почек (ОПП) при воздействии прямых нефротоксинов характеризуется развитием токсического острого канальцевого некроза [1], патогенетически наиболее близкого к ишемическому повреждению почек [2]. Уранил ацетат дигидрат (УАД) представляет собой политропный яд с максимальным действием на проксимальные канальцы нефронов почек [3, 4, 5, 6]. Уран ингибирует натрий-зависимый транспорт глюкозы и неорганического фосфата, активность АТФ-аз, гексокиназы в клетках $\mathrm{S}_{3}$-зоны почечных канальцев. В результате поражения почечных канальцев нефронов развивается острое повреждение

Сивак Константин Владимирович (Sivak Konstantin Vladimirovich), кандидат биологических наук, заведующий отделом доклинических исследований ФГБУ "НИИ гриппа им. А.А. Смородинцева" Минздрава России, kvsivak@gmail.com

Саватеева-Любимова Татьяна Николаевна (Savateeva-Lyubimova Tatiana Nikolaevna), доктор медицинских наук, профессор,

ведущий научный сотрудник лаборатории безопасности лекарственных средств ФГБУ "НИИ гриппа им. А.А. Смородинцева" Минздрава России, drugs_safety@mail.ru

Гуськова Татьяна Анатольевна (Gus'kova Tatiana Anatolevna), заслуженный деятель науки РФ, член-корреспондент РАН, доктор медицинских наук, профессор, заместитель Председателя Всероссийской общественной организации токсикологов, ведущий научный сотрудник отдела доклинических исследований Центра трансфера фармацевтических технологий имени М. В. Дорогова, tagus@rambler.ru

Гусейнов Руслан Гусейнович (Guseinov Ruslan Guseinovich), заведующий 2-м урологическим отделением СПб ГБуз Клиническая больница Святителя Луки), врач первой квалификационной категории, rusfa@yandex.ru 
почек (ОПП) [3 - 8]. В отличие от меркаптосодержащих, гидроксипиридонатных (НОРО) соединений и диэтилентриаминпентаацетата (ДТПА) наибольшую клиническую эффективность при инкорпорации ураном проявил гидрокарбонат натрия (внутривенное и пероральное введение), включенный в стандарт лечения радиационным центром экстренной помощи REAC/TS [9 - 11]. Экспериментально эффективность натрия гидрокарбоната была выявлена в диапазоне доз от 0,1 до 1 г/сут у крыс при отравлении нитратом уранила [9]. Гидрокарбонат ион связывается с ураном в крови, способствует его выведению и предотвращает реабсорбцию урана в почечных канальцах $[9,10,11]$. Одним из перспективных методов интракорпоральной детоксикации при экзогенных отравлениях является «острый» перитонеальный диализ (ПД) $[1,12]$, при котором в качестве полупроницаемой диализной мембраны выступает собственная брюшина пациента. Однако эффективность включения антидотов в раствор для диализа с целью увеличения скорости выведения токсикантов или их метаболитов через брюшину практически не изучена.

Целью данного исследования являлось изучение эффективности ПД в отношении клиренса урана при включении в раствор гидрокарбоната натрия. Для достижения поставленной цели были сформулированы следующие задачи: смоделировать острое отравление нефротоксином УАД на лабораторных животных; провести сеансы ПД, забор сливов и образцов крови, пробоподготовку и анализ уровня урана в диализате; оценить показатели эффективности ПД; провести сравнительную оценку выживаемости животных.

Материалы и методы исследования. Для проведения ПД приготавливали стандартный раствор (А), содержащий стерильные фармакопейные субстанции: глюкозы моногидрат, калия хлорид, натрия хлорид, натрия ацетат тригидрат, и раствор (Б), содержащий, помимо вышеуказанных компонентов, субстанцию натрия гидрокарбоната (Медполимер фирма, ПФК АО, Россия). Растворы готовили из навесок порошков субстанций. Точность весов GR-300 устанавливали до процедуры взвешивания. В асептических условиях навески помещали в мерные колбы, растворяли и доводили до метки водой очищенной. После этого растворы фильтровали через шприц-фильтр с диаметром пор 0,22 мкм и помещали в стерильные маркированные контейнеры. Для опытных серий растворов проводили физико-химическое исследование сходимости результатов с потенциометрическим измерением уровня $\mathrm{pH}$ (ед.), кондуктометрическим определением электропроводности ЕС (мкСм/см) и общего солесодержания TDS $(\mathrm{ppm}=\mathrm{мг/л)}($ Hanna Instruments). Эксперимент in vivo выполнен на самцах крыс Sprague-Dawley с массой тела 260320 г, полученных из питомника лабораторных животных «Пущино». Экспериментальное исследование проведено в соответствии с этическими принципами обращения с лабораторными животными и регулирующими актами. Категория боли: D - боль и страдания, облегчаемые надлежащим способом (применялся ксилазин, 10 и золетил, 50 мг/кг) [13]. Крысы были разделены на 3 группы: 1 группа - животные, получавшие УАД в дозе 20 мг/кг однократно внутрибрюшинно (в/б) (негативный контроль, $\mathrm{n}=8) ; 2$ группа - животные, получавшие УАД в дозе 20 мг/кг однократно в/б за 43 часа до начала стандартного ПД (раствор А) (n=20), 3 группа - животные, получавшие УАД в дозе 20 мг/кг однократно в/б за 43 часа до начала ПД с добавлением гидрокарбоната натрия (раствор Б) $(\mathrm{n}=20)$. Для моделирования ОПП животных за 10 ч лишали корма и вводили однократно в/б раствор УАД в дозе 20 мг/кг $\left(1 \times \mathrm{LD}_{50}\right)$. Наркотизированным животным растворы А и Б вливали ( $\mathrm{V}$ in) в брюшное пространство правого нижнего квадрата через иглу $\mathrm{N} 25 \mathrm{G}$ и силиконовый гепаринизированный катетер с двумя полиэфирными манжетами по системе термостата с температурой $38^{\circ} \mathrm{C}$ (Shellab) c помощью перистальтического насоса Pharmacia (Uppsala) со скоростью 2 мл/мин в эффективном объеме 100 мл/кг и времени экспозиции 40 минут (каждый сеанс) с последующим обратным сливанием через насос в емкости для сбора диализата (V ex). Объемы измеряли. Процедуру ПД проводили в «остром» режиме 1 день в течение 5 часов. Каждая крыса получала суммарно 6 заполнений брюшного пространства и 6 сливов ультрафильтрата. Величину относительной ультрафильтрации вычисляли по соотношению объемов V ex к $\mathrm{V}$ in по каждому сеансу, а затем строили графики линейной регрессии. При необходимости дозу наркотизирующих веществ вводили повторно. Концентрацию изотопа урана- $238\left[{ }^{238} \mathrm{U}\right]$ определяли в суммарном перитонеальном диализате после его СВЧ-минерализации (Start D, MileStone) на масс-спектрометре с индуктивно связанной плазмой ИСП-МС высокого разрешения (Element 2, ThermoScientific) в лаборатории токсикологической химии неорганических соединений (ФГБУН ИТ ФМБА России) под руководством к.Х.н. Иваненко Натальи Борисовны. Концентрацию урана ${ }^{238} \mathrm{U}$ выражали в мкг/л, рассчитывали перитонеальный клиренс урана $\left(\mathrm{PCl}\left[{ }^{238} \mathrm{U}\right]\right)$ в мкг за 6 сеансов диализа по уравнению $\mathrm{PCl}\left[{ }^{238} \mathrm{U}\right]=\mathrm{C}\left[{ }^{238} \mathrm{U}\right]$, мкг/л $\times \mathrm{V}$ ех, л. С целью проведения биохимических исследований у этих же животных отбирали образцы крови из хвостовой вены до начала диализа и после 6-го сеанса диализа, а также на 3-е и 7-е сутки наблюдения. В сыворотке крови и перитонеальном диализате мочевину определяли 
энзиматическим УФ-методом с помощью набора Fluitest UREA фирмы Analyticon на автоматическом биохимическом анализаторе Keylab (BPC BioSed srl). Расчет URR (доля снижения уровня мочевины, \%) проводили по уравнению URR = $\left(1-\mathrm{Ur}_{\text {post }} / \mathrm{Ur}_{\mathrm{pre}}\right) \times 100 \%$, где $\mathrm{Ur}_{\text {pre }}$ концентрация мочевины в крови до начала диализа, $\mathrm{Ur}_{\text {post }}$ концентрация мочевины в крови после диализа. Животных выводили из эксперимента путем плановой эвтаназии, которую проводили на 10 -е сутки путем одномоментной декапитации под легким наркозом (применялся ксилазин и золетил). Для погибших животных проводили вскрытие с установлением причин смерти. Обработку данных выполняли с использованием пакета статистических программ GraphPad Prism 6.0 (США). Для регистрируемых количественных переменных рассчитывали параметры описательной статистики. Данные представлены в виде среднего $(\mathrm{M})$ и его ошибки ( $\pm \mathrm{SE}), 95 \%$ доверительного интервала (95\% С.І.). В фармацевтических исследованиях оценивали коэффициент вариации 10-ти последовательных измерений $\left(\mathrm{CV}_{10}\right)$. Отличия между выборками оценивали с помощью непараметрических критериев Краскела-Уоллиса и Данна (при неравных выборках), Манна-Уитни для парных сравнений и считали значимыми при уровне $\mathrm{p}<0,05$. Для оценки выживаемости строили графики Каплана-Мейера. Достоверность различий кривых выживаемости оценивали с помощью log-rank теста Мантела-Кокса и считали значимыми при уровне $\mathrm{p}<0,05$.

Результаты и обсуждение. Были приготовлены и протестированы растворы А и Б по аналогии с известным раствором «Дианил», в котором лактат натрия заменен на ацетат и исключены соли магния и кальция: раствор А (2,3\% глюкозы, 0,04\% калия хлорида, 0,55\% натрия хлорида, $0,50 \%$ натрия ацетата) и раствор Б (2,3\% глюкозы, $0,04 \%$ калия хлорида, $0,55 \%$ натрия хлорида, $0,50 \%$ натрия ацетата $+1,50 \%$ натрия гидрокарбоната). Анализ физико-химических параметров растворов А и Б показал, что величины их показателей находятся в приемлемом диапазоне ( $\mathrm{pH}$ 6-7,6, ЕС 12-16 мСм/см). Так, $\mathrm{pH}$ составил 5,97 $\pm 0,004$ (95\% C.I. $\left.=5,94-6,00, \mathrm{CV}_{10}=0,24 \%\right)$ для раствора А и 7,68 $\pm 0,01$ (95\% C.I. $=7,61-7,75$, $\mathrm{CV}_{10}=0,43 \%$ ) для раствора Б. Электропроводность ЕС составила для раствора А $11093,4 \pm 44,4$ (95\% C.I. $\left.=10812-11374, \mathrm{CV}_{10}=1,27 \%\right)$, а для Б $-16148 \pm 49,2$ (95\% C.I. $\left.=15836-16458, \mathrm{CV}_{10}=0,96 \%\right)$ мкСм/см. Общее солесодержание TDS, с учетом гашения от присутствия глюкозы, для раствора А составило 5546,5 $\pm 22,2$ (95\% C.I. $\left.=5405-5687, \mathrm{CV}_{10}=1,27 \%\right)$ и Б - 8073,4 $\pm 24,6$ (95\% C.I. $\left.=7917-8228, \mathrm{CV}_{10}=0,96 \%\right)$ мг/л. Разница при введении в состав раствора Б гидрокарбоната натрия составила для $\mathrm{pH} \Delta=1,71$, EC $\Delta=5055$ мкСм $/$ см и TDS $\Delta=2527$ мг/л. С учетом более щелочной реакции раствора Б ожидалось получение терапевтически значимого влияния на состояние метаболического ацидоза, сопровождающего ОПП токсического генеза [1, 5, 7], повышения величины ультрафильтрации за счет более высокой осмолярности, увеличения выживаемости животных, а также предупреждение развития инкапсулированного перитонеального склероза [14].

Для оценки эффективности процедуру ПД проводили, начиная с 43 часа после отравления, когда большая часть урана, поступившего в системный кровоток, подвергается 1 фазе элиминации через почки (быстро выводящаяся фракция с $\mathrm{T}_{\text {биол }}=1,8$ дня). Данные временные условия воспроизводят клиническую ситуацию у людей. Сравнительный анализ эффективности удаления урана $\left[{ }^{238} \mathrm{U}\right]$ из организма за 6 сеансов ПД к 48 часам после отравления показал, что включение в состав раствора Б гидрокарбоната натрия приводит к увеличению скорости выведения токсичного элемента $\mathrm{PCl}\left[{ }^{238} \mathrm{U}\right]$ (перитонеальный клиренс) на 276,2\% (p=0,0286, критерий МаннаУитни) по сравнению с раствором А. Полученные данные представлены на рисунке 1.

Динамика ультрафильтрации (Vex/Vin, отн. ед.) во 2-й группе животных характеризовалась среднечасовой скоростью 1,06 отн.ед., линейным ростом от 1 до 3 сеанса (угол наклона линейной регрессии $40^{\circ}$ ) с выходом на плато к 4 сеансу ПД $(+27,4 \%$ ко 2-му сеансу, $+41,1 \%$ к 3-му сеансу и

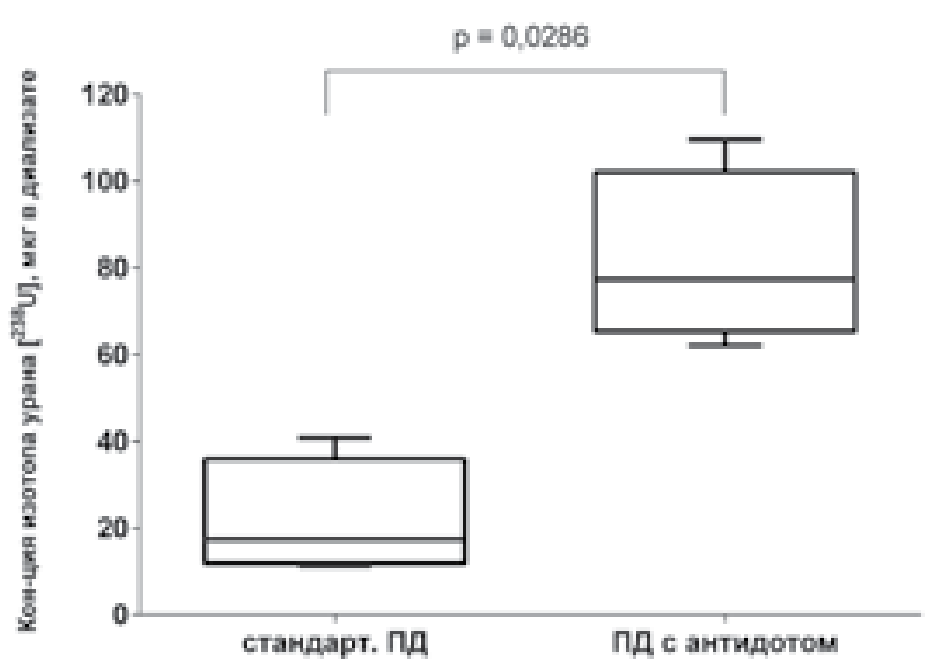

Рис. 1. Величина перитонеального клиренса PCI[238U] у крыс с острым повреждением почек токсического генеза через 48 часов после отравления УАД на фоне введения растворов А (стандартный ПД) и Б (ПД с антидотом). По оси абсцисс экспериментальные группы, по оси ординат суммарное количество удаленного урана $\left[{ }^{238} \mathrm{U}\right]$ за сеансы диализа. 

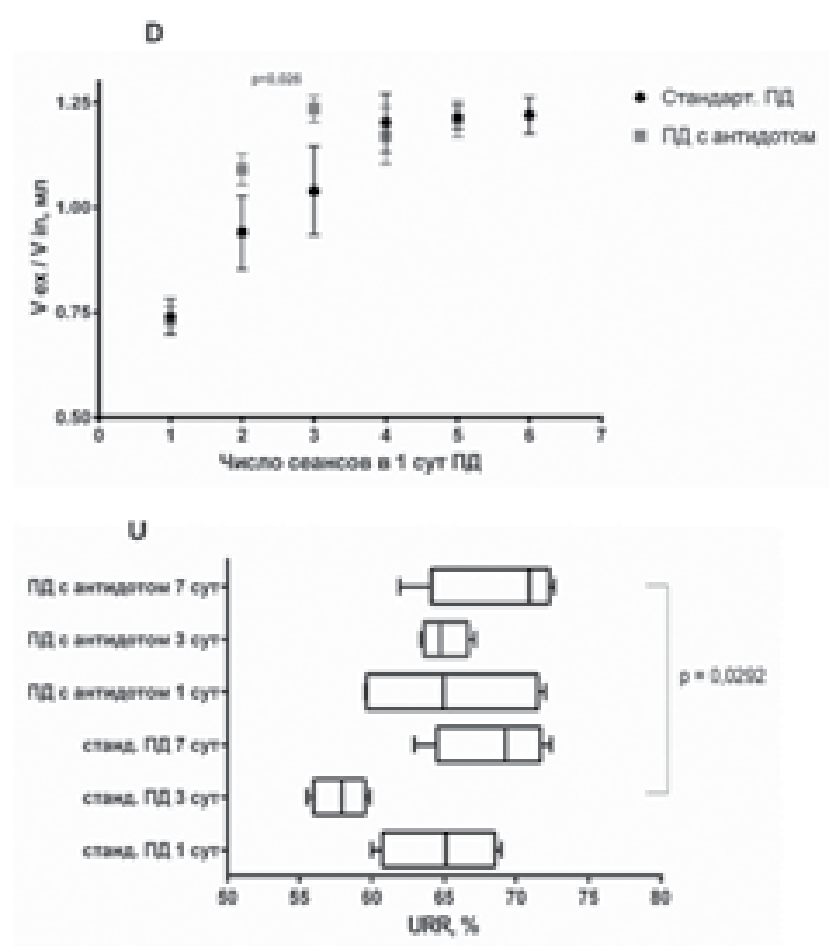

Рис. 2. Динамика ультрафильтрации в первый день диализа (D) и доля снижения уровня мочевины URR, $\%$ на 1, 3 и 7 сутки (U) у крыс с острым повреждением почек токсического генеза на фоне введения растворов A (стандартный ПД) и Б (ПД с антидотом). По оси абсцисс в D число сеансов диализа, в U - величина URR, по оси ординат - в D индекс ультрафильтрации, в U экспериментальные группы.

+62,3\% к 4-му сеансу). В 3-й группе крыс, получавших ПД раствором Б, динамика ультрафильтрации (рис. 2) характеризовалась среднечасовой скоростью 1,12 отн.ед., линейным ростом от 1 до 3 сеанса (угол наклона линейной регрессии $70^{\circ}$ ) c выходом на плато к 3 сеансу ПД (+48,7\% ко 2-му сеансу, $+68,5,1 \%$ к 3-му сеансу). Статистически достоверные различия отмечали при сравнении групп ПД раствором А, 1-й сеанс vs. ПД раствором Б, 3-й сеанс ( $\mathrm{p}=0,026)$, ПД раствором А, 1-й сеанс vs. ПД раствором Б, 6-й сеанс $(\mathrm{p}=0,018)$, ПД раствором Б, 1-й сеанс vs. ПД раствором Б, 3-й сеанс ( $\mathrm{p}=0,024)$, и ПД раствором Б, 1-й сеанс vs. ПД раствором Б, 6-й сеанс ( $\mathrm{p}=0,016)$.

Доля снижения уровня мочевины (URR) составила более $60 \%$ (рис. 2). Так, в группе № 2 у крыс, получавших ПД раствором A, величина URR в 1-е сутки составила $64,8 \%$, что рассматривалось как адекватный режим диализа. При наблюдении на 3-е сутки величина URR несколько снижалась и составила $57,8 \%$, а при наблюдении на 7-е сутки снова увеличивалась до 68,5\%. Во 3-ей группе крыс, получавших ПД раствором Б, величина URR составила $65,4 \%$ в 1 -е сутки, $65 \%$ в 3 -е сутки и $69,1 \%$ на 7-е сутки наблюдения. При этом ста- тистически значимые различия были выявлены при сравнении групп ПД раствором А, 3-е сутки vs. ПД раствором Б, 7-е сутки ( $\mathrm{p}=0,029)$. Полученные результаты представлены на рисунке 2.

Результаты теста Мантела-Кокса показали, что в отличие от диализа раствором А (погибло 10 из 20 крыс, $\mathrm{p}=0,0452$ по сравнению с группой негативного контроля) ПД с добавлением гидрокарбоната натрия (раствор Б) способствовал достоверному увеличению постдиализной выживаемости крыс (погибло 4 из 20, $\mathrm{p}=0,0018$ по сравнению с группой негативного контроля, $\mathrm{p}=0,0425$ по сравнению с диализом раствором А). Данные отражены на рисунке 3. Смертность животных в группе негативного контроля (без лечения) составила 75\% (6/8), что соответствовало ожидаемой смертности от введения расчетной дозы токсиканта. Концентрация мочевины в крови отравленных крыс в премортальный период составляла более 40 ммоль/л. При вскрытии погибших крыс из всех экспериментальных групп были отмечены признаки гипергидратации легких, дилатация камер сердца, отек головного мозга, развившиеся вследствие симметричного кортикального некроза почек. Нами высказано предположение, что при базальном высоком уровне мочевины к концу вторых суток после острого отравления ураном (>40 ммоль/л) эффективность любых методов интра- или экстракорпорального очищения не будет способствовать увеличению выживаемости из-за индивидуальной повышенной восприимчивости к действию данного нефротоксина.

Полученные результаты продемонстрировали, что включение гидрокарбоната натрия в состав диализирующего раствора способствует увеличению доли удаляемого урана $\left[{ }^{238} \mathrm{U}\right]$ из организма животных в 4 раза за счет связывания в более прочный гидрокарбонатный комплекс урана (константа стабильности уранил-бикарбоната Kstab $=1,1 \times 10^{18}$ ), а также повышения скорости ультрафильтрации и удаления мочевины за счет большей осмолярности раствора. В свою очередь увеличение перитонеального клиренса урана способствует повышению уровня выживаемости отравленных животных. Таким образом, гидрокарбонат натрия можно считать эффективным антидотом в схеме применения при перитонеальном диализе в случае острого отравления УАД.

Заключение. При отравлении соединениями урана токсический элемент находится в циркуляции в виде равновесного соотношения комплексов с альбумином, липопротеинами и гидрокарбонатом плазмы крови. Последний комплекс является наиболее стабильным, что лежит в основе использования гидрокарбоната натрия в качестве антидота при отравлении нефроток- 


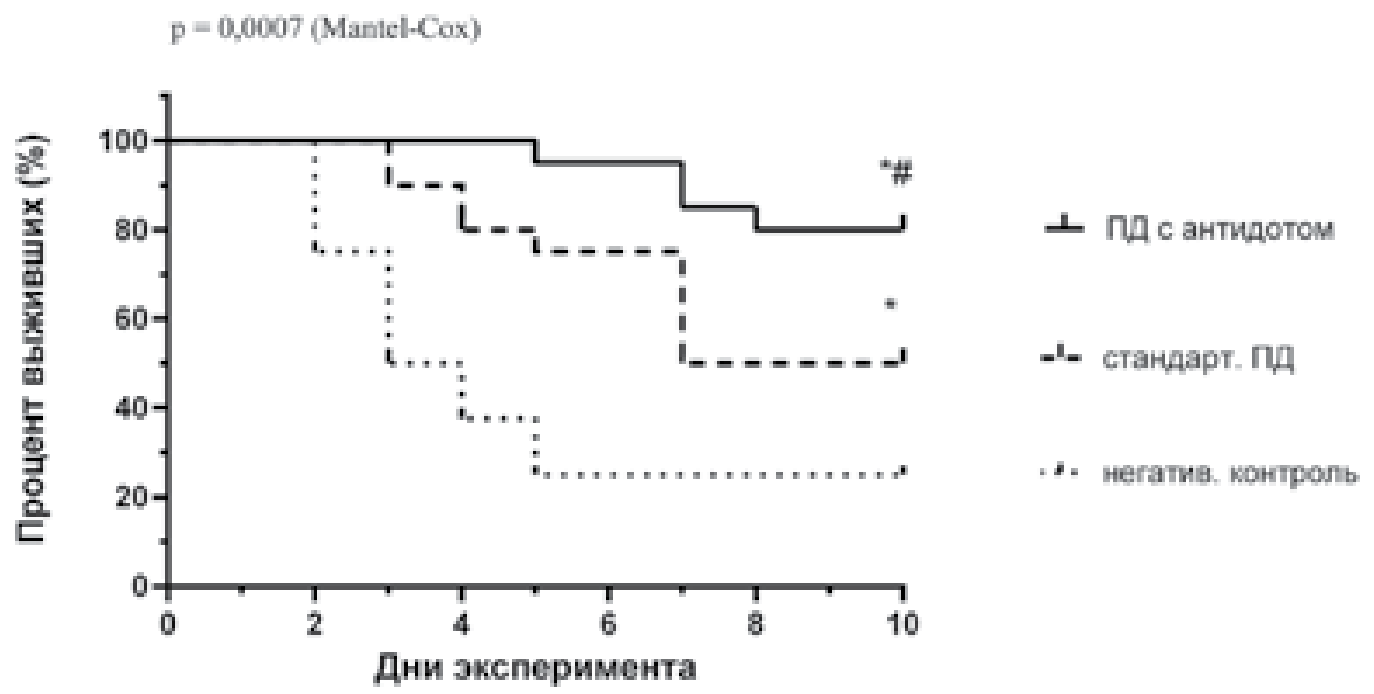

Рис. 3. Графики выживаемости Каплана-Мейера крыс с острым повреждением почек токсического генеза на фоне введения растворов А (стандартный ПД) и Б (ПД с антидотом). По оси абсцисс дни эксперимента, по оси ординат - доля выживших крыс в \%.

сичным ураном. При удалении комплекса с гидрокарбонатом, например, при фильтрации в почках, равновесное соотношение нарушается, и новые порции токсиканта при продолжении введения гидрокарбоната натрия отщепляются из комплексов с альбумином и липопротеинами, в результате чего снижается степень повреждения органов-мишеней. Введение в состав рас-

\section{СПИСОК ЛИТЕРАТ УРЫ}

1. Ермоленко В.М., Николаев А.Ю. Острая почечная недостаточность: руководство. М.: ГЭОТАР-Медиа, 2010. - 240 c. 2. Гусейнов Р.Г., Попов С.В., Горшков А.Н., Сивак К.В., Мартов А.Г. Влияние длительности тепловой ишемии почки на восстановление фильтрационной функции в эксперименте. Урология. 2017. № 6. C. $20-29$. DOI: $10.18565 /$ urology.2017.6.20-29

3. Сивак К.В., Саватеева-Любимова Т.Н. Биохимическая характеристика поражения почек при остром отравлении солями урана. Медицина экстремальных ситуаций, М. 2010; 4(34):96-104

4. Способ моделирования комбинированного воздействия обедненным ураном / Пат. № 2561295 Рос. Федерация МПKG09B 23/28 (2006.01) / Сивак К.В., Стосман К.И., Любишин М.М., Наволоцкий Д.В., Саватеева-Любимова Т.Н. - 2012.

5. Кудаева Э.Ф., Минасян В.В., Воронцова 3.А. Адаптивные возможности органов с разной скоростью обновления после воздействия обедненного урана в эксперименте. Вестник новых медицинских технологий. Электронное издание. 2017; 4:172-177.

6. Сивак К.В., Стосман К.И., СаватееваЛюбимова Т.Н. Функциональное состояние почек и иммунологические нарушения при остром комбинированном воздействии обедненным ураном. Мед.-биол и соц.-психол. пробл. безопасности в чрезв. ситуациях. 2017; 2: 93-98. DOI 10.25016/2541-7487-2017-0-2-93-98. 7. Воронцова З.А., Кудаева Э.Ф., Селявин С.С., Минасян В.В. Интегративные биоэффекты обедненного урана. Научно-медицинский вестник Центрального Черноземья. 2018; 73:125-129. 8. Сивак К.В., Саватеева-Любимова Т.Н., твора для ПД гидрокарбоната натрия в качестве антидота способствовало увеличению перитонеального клиренса урана $\mathrm{PCl}\left[{ }^{238} \mathrm{U}\right]$ на 276,2\% по сравнению со стандартным раствором, линейному росту ультрафильтрации, снижению уровня гиперазотемии, что сопровождалось достоверным увеличением постдиализной выживаемости крыс.

\section{REFERENCES:}

1. Yermolenko V.M., Nikolaev A.D. Acute renal failure. - Moscow: GEOTAR-Media, 2010. - 240 p. (in Russ.)

2. Guseinov R.G., Popov S.V., Gorshkov A.N., Sivak K.V., Martov A.G. Effects of the of renal warm ischemia time on the recovery of filtration function in the experiment. Urology. 2017; 6:20-29. DOI: 10.18565 / urology.2017.6.20-29 (in Russ.)

3. Sivak K.V., Stosman K.I., SavateevaLyubimova T.N. Biochemical profile of rena damage in acute intoxication by depleted

uranium soluble salts. Medicine of Extreme of New Medical Technologies. 2017; Situations. 2010; 4(34):96-104 (in Russ.) 4:172-177 (in Russ.) 4. The method of modeling the combined effects of depleted uranium / patent № 2561295 Russian Federation: MPKG09B 23/28 (2006.01) / Sivak K.V., Stosman K.I., Lyubishin M.M., Navolockij D.V. Savateeva-Lyubimova T.N. - 2012. (in Russ.)

5. Kudaeva E.F., Minasyan V.V., Vorontsova Z.A. Adaptive opportunities of organs

with different rate of updates after lowed uranium impact in the experiment. Journ
Гуськова Т.А. Методические подходы к раннему выявлению острого повреждения почек токсического генеза на основе динамики некоторых биомаркеров. Токсикологический вестник. 2019; (2):37-42.

. Ohmachi Y, Imamura T, Ikeda M, et al. Sodium bicarbonate protects uranium-induced acute nephrotoxicity through uranium-decorporation by urinary alkalinization in rats [published correction appears in J Toxicol Pathol. 2016 Jan;29(1):74]. J Toxicol Pathol. 2015; 28(2):65-71. doi:10.1293/tox.2014-0041 10. Yue YC, Li MH, Wang HB, Zhang BL, He W. The toxicological mechanisms and detoxification of depleted uranium exposure. Environ Health Prev Med. 2018; 23(1):18. Published 2018 May 16. doi:10.1186/ s12199-018-0706-3

11. Smith SW. The role of chelation in the treatment of other metal poisonings. J Med
Toxicol. 2013; 9(4):355-369. doi:10.1007/ s13181-013-0343-6

12. Vila Cuenca M, Keuning ED, Talhout W, et al. Differences in peritoneal response after exposure to low-GDP bicarbonate/ lactate-buffered dialysis solution compared to conventional dialysis solution in a uremic mouse model. Int Urol Nephrol. 2018 50(6):1151-1161. doi:10.1007/s11255018-1872-3

13. Директива 2010/63/EU европейского парламента и совета европейского союза по охране животных, используемых в научных целях. Rus-LASA. СПб. 2012; 48 с.

14. Kitamura M, Nishino T, Obata Y, Ozono Y Koji T, Kohno S. New insights into therapeutic strategies for the treatment of peritoneal fibrosis: learning from histochemical analyses of animal models. Acta Histochem Cytochem. 2014;47(4):133-143. doi:10.1267/ ahc. 14025
6. Sivak K.V., Stosman K.I., SavateevaLyubimova T.N. Functional state of kidneys and immunological disorders associated with acute combined exposure to deplete uranium. Medical-Biological and SocioPsychological Problems of Safety in Emergency Situations. 2017: 2: 93-98. Ol 10.25016/2541-7487-2017-0-2-93 98. (in Russ.) Sodium bicarbonate protects uraniumS.S., Minasyan V.V. Integrative bioeffects of uranium-decorporation by urinary 
alkalinization in rats [published correction appears in J Toxicol Pathol. 2016 Jan;29(1):74]. J Toxicol Pathol. 2015; 28(2):65-71. doi:10.1293/tox.20140041

10. Yue YC, Li MH, Wang HB, Zhang BL, $\mathrm{He}$ W. The toxicological mechanisms and detoxification of depleted uranium exposure. Environ Health Prev Med. 2018;
23(1):18. Published 2018 May 16 doi:10.1186/s12199-018-0706-3 11. Smith SW. The role of chelation in the treatment of other metal poisonings. J Med Toxicol. 2013; 9(4):355-369. doi:10.1007/s13181-013-0343-6

12. Vila Cuenca M, Keuning ED, Talhout et al. Differences in peritoneal response after exposure to low-GDP bicarbonate/

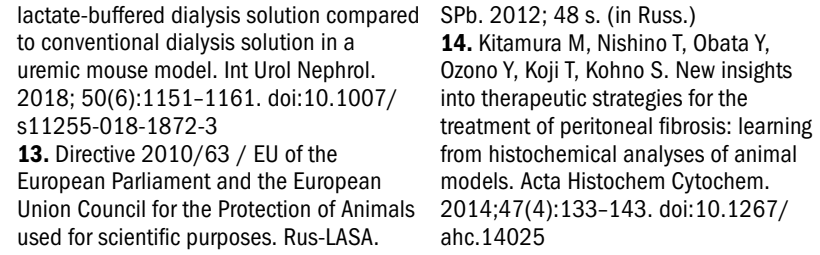

SPb. 2012; 48 S. (in Russ.) tional dialysis solution in a 14. Kitamura M, Nishino T, Obata Y, into therapeutic strategies for the ment of peritoneal fibrosis: learning models. Acta Histochem Cytochem. ahc. 14025

\title{
REDUCTION OF NEPHROTOXICITY BY PERITONEAL DIALYSIS WITH ADDITION OF SODIUM HYDROCARBONATE DURING POISONING WITH URANIUM ACETATE DIHYDRATE IN RAT
}

\author{
${ }^{1}$ A.A. Smorodintsev Research Institute of Influenza, Ministry of Healthcare of the Russian Federation, 197376, Saint Petersburg, \\ Russian Federation \\ ${ }^{2}$ M.V. Dorogov Yaroslavl Center for the Transfer of Pharmaceutical Technologies, K.D. Ushinsky Yaroslavl State Pedagogical \\ University, 150010, Yaroslavl, Russian Federation \\ ${ }^{3}$ Clinical Hospital of St. Luka (Saint Petersburg Clinical Hospital of St. Luka), 194044, Saint Petersburg, Russian Federation
}

The article presents the results of an experimental study on rats' poisoning with uranyl acetate dihydrate $\left(1 \times \mathrm{DL}_{50}\right)$. The aim of this work was to investigate the effectiveness to the sodium bicarbonate additive to the composition of the solution for peritoneal dialysis in relation to uranium clearance and survival of rats. The procedure of peritoneal dialysis was carried out in the "acute" mode in 1 day for 5 hours. Each rat received a total of 6 abdominal fillings and 6 ultrafiltration drains. The differences for $\mathrm{pH} \Delta=1.71, \mathrm{EC} \Delta=5055 \mu \mathrm{S} / \mathrm{cm}$ and TDS $\Delta=2527 \mathrm{mg} / \mathrm{L}$ have been observed by addition of sodium bicarbonate $(\mathrm{B}, 1.5 \%)$ to the standard solution. The administration of solution $\mathrm{B}$ led to an increase in the rate of peritoneal clearance of uranium $\mathrm{PCl}^{238} \mathrm{U}$ by $276.2 \%(\mathrm{p}=0.0286$, MannWhitney criterion) compared to standard solution A without sodium bicarbonate. The dynamics of ultrafiltration were characterized by a linear growth from 1 to 3 sessions (the slope of the linear regression is $70^{\circ}$ ) to an exit to the plateau by 3 sessions. The URR was $65.4 \%$ in the $1^{\text {st }}$ day, $65 \%$ in the $3^{\text {rd }}$ day, and $69.1 \%$ in the $7^{\text {th }}$ day. The results of the Mantel-Cox test have showed that peritoneal dialysis with the addition of sodium bicarbonate as an antidote (solution B) contributed to a significant increase in postdialysis survival of rats $(\mathrm{p}=0.0018$ compared to the negative control group, $\mathrm{p}=0.0425$ compared to dialysis solution A).

Keywords: uranium, ${ }^{238} \mathrm{U}$, rats, acute kidney injury, “acute” peritoneal dialysis, peritoneal clearance, ultrafiltration, $P C l^{238} U, U R R$.

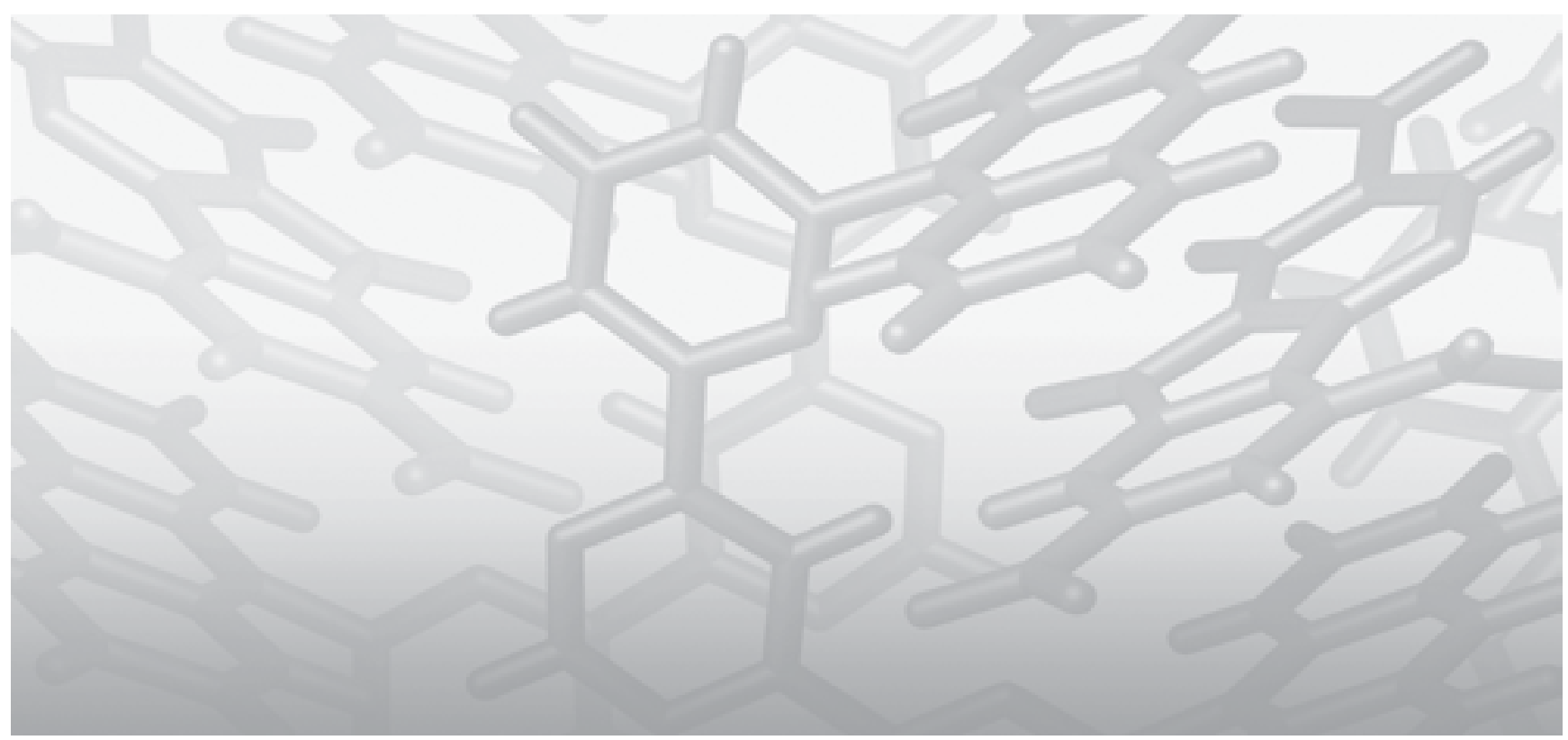

